\title{
Mechanisms controlling warm water volume interannual variations in the equatorial Pacific: diabatic versus adiabatic processes
}

\author{
M. Lengaigne $\cdot$ U. Hausmann $\cdot$ G. Madec $\cdot$ \\ C. Menkes $\cdot$ J. Vialard $\cdot$ J. M. Molines
}

\begin{abstract}
Variations of the volume of warm water above the thermocline in the equatorial Pacific are a good predictor of ENSO (El Niño/Southern Oscillation) and are thought to be critical for its preconditioning and development. In this study, the Warm Water Volume (WWV) interannual variability is analysed using forced general circulation model experiments and an original method for diagnosing processes responsible for WWV variations. The meridional recharge/discharge to higher latitudes drives $60 \%$ of the ENSO-related equatorial WWV variations, while diabatic processes in the eastern equatorial Pacific account for the remaining $40 \%$. Interior meridional transport is partially compensated by western boundary transports, especially in the southern hemisphere. Diabatic equatorial WWV formation (depletions) during La Niña (El Niño) are explained by enhanced (reduced) diathermal transport through enhanced (reduced) vertical mixing and penetrating solar forcing at the $20^{\circ} \mathrm{C}$ isotherm depth. The respective contribution of diabatic and adiabatic processes
\end{abstract}

M. Lengaigne · G. Madec · C. Menkes · J. Vialard Laboratoire d'Océanographie Expérimentation et Approches Numériques, CNRS, UPMC, IRD, Paris, France

U. Hausmann

Department of Physics, Imperial College, London, UK

G. Madec

National Oceanographic Centre, Southampton, UK

J. M. Molines

Laboratoire Ecoulements Geophysiques et Industriels, CNRS, UJF, INP, Grenoble, France

M. Lengaigne $(\square)$

Couloir 45-55, 4ème étage, Case 100, 4 Place Jussieu, 75252 Paris Cedex 05, France

e-mail: lengaign@lodyc.jussieu.fr during build-ups/depletions strongly varies from event-toevent. The WWV build-up during neutral ENSO phases (e.g. 1980-1982) is almost entirely controlled by meridional recharge, providing a text-book example for the recharge/discharge oscillator's theory. On the other hand, diabatic processes are particularly active during the strongest La Niña events $(1984,1988,1999)$, contributing to more than $70 \%$ of the WWV build-up, with heating by penetrative solar fluxes explaining as much as $30 \%$ of the total build-up due to a very shallow thermocline in the eastern Pacific. This study does not invalidate the recharge/ discharge oscillator theory but rather emphasizes the importance of equatorial diabatic processes and western boundary transports in controlling WWV changes.

Keywords El Niño/Southern Oscillation - Warm water volume - Equatorial Pacific - Western boundary currents . Solar penetration $\cdot$ Vertical mixing

\section{Introduction}

The El Nino/Southern Oscillation (ENSO) is the dominant mode of climate variability at interannual time scales, and impacts weather patterns across the globe (McPhaden et al. 2006a). The physical processes behind ENSO have been studied intensively over the past decades (e.g. Wang and Picaut (2004) and Collins et al. (2010) for reviews). The equatorial Warm Water Volume (WWV), generally defined as the volume of water above $20^{\circ} \mathrm{C}$ in the equatorial Pacific, has been suggested for long as a key ingredient in ENSO dynamics (Cane and Zebiak 1985; Wyrtki 1985; Springer et al. 1990). These studies show that an El Niño/ La Niña is associated with a zonal redistribution of water along the equator, and preceded by a build-up/depletion of 
WWV. Jin (1997a, b) built on these findings to propose one of the leading ENSO theories: the "recharge-discharge oscillator". In this paradigm, WWV leads the SST evolution by a quarter of a period and the cyclic nature of ENSO arises from the disequilibrium between zonal winds and WWV anomalies. Using observed measurements of WWV, Sea Surface Temperature (SST) and zonal wind, Meinen and McPhaden (2000) further showed that the recharge discharge theory was consistent with their observational analysis, with WWV preceding SST variations by 6 months to one year.

The WWV has been shown to be a useful predictor of ENSO (e.g. McPhaden et al. 2006b; Izumo et al. 2010). It is therefore of interest to understand the physical mechanisms responsible for these warm water volume changes in the equatorial strip. The recharge-discharge theory originally assigns the recharge and discharge of the equatorial Pacific to interior meridional transports between the equatorial strip and higher latitude on ENSO time-scale. WWV variations can however be driven by both anomalous horizontal transports (in the interior of the domain or along the western boundaries) and anomalous diathermal transports (through changes in vertical turbulent mixing and penetrative solar forcing along $20^{\circ} \mathrm{C}$ isotherm). Several studies have attempted to quantify the main contributors (i.e. horizontal and diathermal transports) to WWV changes from observations (Meinen and McPhaden 2001; Alory and Delcroix 2002; Clarke et al. 2007; Bosc and Delcroix 2008) and model outputs (Brown and Fedorov 2010), with contrasted results. Using data from the Tropical Atmosphere Ocean moorings, Meinen and McPhaden (2001) found that the build-up of WWV between the weak 1994-1995 El Niño and the onset of the strong 1997-1998 El Niño resulted primarily from an anomalous transport in the western-central Pacific. Their results however suggest that downward diathermal mass flux contributed to about half of the warm water discharge during the 1997-1998 El Niño. The importance of diathermal processes in controlling WWV changes have been further highlighted by Clarke et al. (2007) who suggest that diathermal transports cannot be neglected but are largely balanced by boundary transports in the western Pacific. Besides, although they did not explicitly quantify the role of diathermal transports, Alory and Delcroix (2002) and Bosc and Delcroix (2008) concluded that interior meridional transport alone can account for WWV changes.

However, those observational studies are based on a limited amount of data and rely on available observations to estimate geostrophic and Ekman transports. The residual from these two quantities is then attributed to diathermal transport. Important error bars on the estimated horizontal convergences make it however difficult to confidently attribute the observed imbalances between WWV changes and transport to the role of oceanic physics. Analysing
Ocean General Circulation Model (OGCM) outputs is an alternative approach to quantify the contributors to WWV changes: it allows an accurate calculation of the diathermal transports and avoids potential errors of observational studies. The recent study of Brown and Fedorov (2010) based on an analysis of MOM3 outputs suggested that WWV variations due to diapycnal transport are small in the eastern Pacific and negligible in the western and central Pacific on ENSO timescales. In the present study we propose to thoroughly quantify the mutual roles of exchange with higher latitudes and formation of warm water by thermodynamic processes in the equatorial band using a different ocean model. There are three main incentives to perform this new modelling study after the one of Brown and Fedorov (2010). First, the quantification of the various processes may be dependent on the model parameterizations, resolution, forcing... A similar analysis using NEMO OGCM (Madec 2008) has therefore been performed and the sensitivity of the model results to the resolution is briefly discussed by comparing three configurations only differing in their horizontal resolution (from $2^{\circ}$ to $14^{\circ}$ ). Second, while Brown and Fedorov (2010) focused on the 1993-1998 period (as in Meinen and McPhaden's (2001) study), we extend the analysis over a longer period, i.e. 1976-2004, to assess how the respective contribution of the main mechanisms controlling the WWV evolution may vary from event-to-event (El Niño/La Niña, intense/moderate events). Lastly, in all the above studies investigating WWV changes, the influence of penetrative solar radiation was not evaluated. However, several recent studies suggest that the solar penetration formulation can significantly influence ENSO properties (e.g. Strutton and Chavez 2004; Wetzel et al. 2006; Lengaigne et al. 2007). To account for this additional contributor, we apply an original method, following Walin (1982) and improved by Iudicone et al. (2008), which allows diagnosing all the processes that contribute to WWV variations including solar heating.

This paper is organised as follows. Section 2 describes the model experiment and the diagnostic used to quantify the different factors that control the evolution of the equatorial Pacific WWV. Section 3 validates modelled WWV variability against available observations. Section 4 discusses the processes that contribute to equatorial WWV variations on interannual time scales. Discussion of the results and a conclusion are respectively provided in Sects. 5 and 6.

\section{Data and methods}

2.1 The ocean model and forcing datasets

The numerical simulations analysed in this study are part of the DRAKKAR hierarchy of global configurations (The 
Drakkar group 2007) and detailed in Brodeau et al. (2010). The Ocean General Circulation Model (OGCM) is the recent version (3.0) of the NEMO (Nucleus for European Modelling of the Ocean) OGCM (Madec 2008), comprising the ocean model formerly known as OPA, coupled to the Louvain-la-Neuve sea-ice model (LIM) (Timmermann et al. 2005). The model is based on the standard primitive equations, uses a free surface formulation (Roullet and Madec 2000) and computes the density from potential temperature, salinity and pressure using the Jackett and McDougall (1995) equation of state. This OGCM has been extensively validated in uncoupled mode (e.g. Vialard et al. 2001; Lengaigne et al. 2003; Cravatte et al. 2008) and coupled mode (e.g. Lengaigne et al. 2006) in the tropics where it succeeds in reproducing the basin wide structures of currents, sea level and temperature and accurately simulates the equatorial dynamics.

In this paper, we analyze the highest resolution experiment from a series of four simulations that only differ by their oceanic horizontal resolution: two versions with coarse $2^{\circ}$ and $1^{\circ}$ resolution (ORCA-R2 and ORCA-R1), a higher $1 / 2^{\circ}$ resolution (ORCA-R05) and an eddy permitting $1 / 4^{\circ}$ resolution (ORCA-R025). Comparisons with lower resolution experiments (ORCA-R2 and ORCA-R05) will be briefly discussed in Sect. 5. The horizontal grids of these configurations are based on Mercator grids (i.e. the same zonal and meridional grid spacing). Two numerical inland poles have been introduced in order to remove the North Pole singularity from the computational domain, so that the departure from the Mercator grid starts at $20^{\circ} \mathrm{N}$. In the tropics, a local transformation is applied to ORCA-R2 in order to refine the meridional resolution, increasing up to $0.5^{\circ}$ at the equator. The common vertical grid of the configurations used has 46 levels with a 6-m spacing at the surface increasing to 250-m in the deep ocean. Bathymetry is represented with partial steps and an enstrophy-energyconserving momentum advection scheme is used (Barnier et al. 2006; Penduff et al. 2007; Le Sommer et al. 2009).

In order to evaluate the influence of thermodynamic water mass formation and consumption, the mixing parametrization and the forcing dataset are of great importance. As far as mixing is concerned, vertical Eddy diffusivity (and viscosity) coefficients are computed from a turbulence closure scheme (Blanke and Delecluse 1993) allowing high values in the surface boundary layer as well as a minimum value of $10^{-5} \mathrm{~m}^{2} \mathrm{~s}^{-1}$ in the thermocline. Convective mixing is simulated by setting the vertical viscosity and diffusivity coefficients to $100 \mathrm{~m}^{2} \mathrm{~s}^{-1}$ in statically unstable regions. Tracers lateral mixing is of Laplacian type and acts along isoneutral surfaces, with diffusivity coefficient function of the grid spacing. At the equator, it varies from $1,000 \mathrm{~m}^{2} \mathrm{~s}^{-1}$ for ORCA-R2 to $200 \mathrm{~m}^{2} \mathrm{~s}^{-1}$ for ORCA-R025. In these experiments, a monochromatic formulation of the penetrative solar irradiance $I_{p e n}(z)$ is assumed following a single exponential profile (Paulson and Simpson 1977):

$I_{p e n}(z)=Q_{s r}(1-R) e^{-Z / h_{0}}$

where the value $h_{0}$ represents the e-folding depth scale for the penetration of irradiance over the penetrative wavebands, set to $23 \mathrm{~m}$ in our study and $\mathrm{R}=0.58$. This value correspond to a Type I water in Jerlov's (1968) classification (oligotrophic waters).

In these experiments, the model is forced from 1958 to 2007 with the Drakkar Forcing Set \#3 (DFS3) described in detail in Brodeau et al. (2010). The starting point of DFS3 is the CORE dataset developed by Large and Yeager (2004) and used to intercompare various global ocean components of coupled system (Griffies et al. 2009). To calculate latent and sensible heat fluxes, the CORE bulk formulae algorithm is used, with surface atmospheric state variables derived form ERA40 reanalysis and ECMWF analysis after 2002 (air temperature, humidity and winds at $10 \mathrm{~m}$ ). Corrections are performed on these selected input fields to correct temporal discontinuities and yield better agreement with some recent high quality data. Radiation fluxes are based on the CORE v1 dataset, using a corrected ISCCP-FD radiation product (Zhang et al. 2004) available from 1984. Before 1984, climatology is imposed, which leads to better results than the use of reanalyses data. Precipitation is derived from the GXGXS dataset (Large and Yeager 2004), based on the blending of several existing products from 1979. Before 1979, its climatology is imposed. No surface temperature restoring is performed and a salinity restoring, corresponding to a relaxation time scale of 33 days for $10 \mathrm{~m}$, is used even under sea ice. In the following, analysis of these simulations are restricted to the 1976-2004 period.

\subsection{Volume budget diagnostic}

The role of mixing and forcing in the transformation of water masses is quantified using the thermodynamical method of Iudicone et al. (2008). It is a generalisation of Walin's (1982) approach that first derived elegant relations between water mass formation and diffusive and radiative (non-advective) heat fluxes, combining heat and volume budgets for an isothermal layer. Iudicone et al. (2008) included internal buoyancy sources (to account for the solar penetrative irradiance) in the estimation of transformations. Therefore, by using this method, we are able to quantify the contribution of each component to the WWV evolution in the OGCM.

Briefly, the methodology is as follows. Assuming incompressibility (as it is done in NEMO model), the equation for the evolution of the volume $V_{\theta}$ bounded from below by an isotherm $\theta$ can be expressed as: 
$\frac{\partial V_{\theta}}{\partial t}=\underbrace{\frac{\partial D}{\partial \theta}+\frac{\partial F}{\partial \theta}}_{\text {Diabatic Processes }}+\underbrace{\Psi_{\theta}+E_{\theta}}_{\text {Adiabatic Processes }}$

where $\partial D / \partial \theta$ and $\partial F / \partial \theta$ are the water-mass formations driven by ocean mixing and atmospheric forcing, respectively (referred to as diabatic processes in the following) and $\Psi_{\theta}$ and $E_{\theta}$ are the volume fluxes of water entering/ exiting the domain $V_{\theta}$ across the open boundaries and sea surface respectively (referred to as adiabatic processes). A detailed derivation of this equation of volume evolution can be found in Iudicone et al. (2008), using the same formalism.

The volume of water entering/exiting the domain at the open boundaries $\left(5^{\circ} \mathrm{N}\right.$ and $5^{\circ} \mathrm{S}$ in our case) can be easily written as:

$\Psi_{\theta}=\iint_{\text {boundaries }_{\theta>\theta_{0}}} \mathbf{u} \mathrm{d} \mathbf{S}$

where $\mathbf{u}$ is a velocity vector and $\mathrm{d} \mathbf{S}$ is a vector directed towards $V_{\theta}$.

Similarly, evaporation and precipitation act to modulate the volume of water entering/exiting the domain at the surface, so that the influx of water through the sea-surface can be expressed as:

$E_{\theta}=\iint_{S_{\theta>\theta_{0}}}(P-E) \mathrm{d} S$

where $P$ is precipitation and $E$ evaporation. The mean surface freshwater input is associated with volume transport of $0.15 \mathrm{~Sv}$ with a $0.1 \mathrm{~Sv}$ interannual standard deviation. As originally suggested by Meinen and McPhaden (2001), this term is negligible compared to the total WWV balance and will not be discussed further. Following Iudicone et al. (2008), the formation of warm water volume by atmospheric forcing $\partial F / \partial \theta$, including the effect of solar penetration, can be written as:

$\frac{\partial F}{\partial \theta}=\frac{\partial}{\partial \theta} \iint_{S_{\theta>\theta_{0}}} \frac{\left(Q-I_{0}\right)}{c_{v}} \mathrm{~d} S+\frac{\partial}{\partial \theta} \iiint_{V_{\theta>\theta_{0}}} \frac{\partial_{z} I(z)}{c_{v}} \mathrm{~d} V$

where $Q$ is the net heat flux across the sea surface, $\mathbf{I}(z)$ is the solar irradiance flux that reaches the depth $z$, $I_{\mathrm{o}}=I(z=0)$, is the total surface solar radiation, $c_{v}$ is the heat capacity per unit volume of seawater. The first term on the right hand side of the equation has a negligible influence on the WWV defined with the $20^{\circ} \mathrm{C}$ isotherm as this isotherm mainly outcrops poleward of $5^{\circ} \mathrm{N}-5^{\circ} \mathrm{S}$. Atmospheric forcing can therefore only modify WWV via penetrating solar radiation.

Finally, away from the ocean surface, turbulent heat fluxes mix warm waters from above with cold waters below. If they converge on the isotherm, warm water is formed. This water mass formation through ocean mixing is given by:

$\frac{\partial D}{\partial \theta}=\frac{\partial}{\partial \theta} \iiint_{V_{\theta>\theta_{0}}} \nabla \cdot(\mathrm{k} \nabla \theta) \mathrm{d} V$

where $\mathbf{k}$ is the diffusive tensor.

Since we can exactly diagnose volume time variations and formation of warm water by atmospheric forcing and domain boundary fluxes $\left(\Psi_{\theta}\right.$ and $\left.E_{\theta}\right)$, the formation by turbulent diffusion will be estimated in the following as a residual and we will refer to this term as "physics".

This method has been applied to all isotherms between 16 and $24^{\circ} \mathrm{C}$ with an interval of $0.5^{\circ} \mathrm{C}$. Computations have been made on 5-day averages model outputs. Differences between the computation of volume budgets from 5-day model outputs and from outputs at the model time-step arising from nonlinearities are negligible (Iudicone et al. 2008). Volume time derivations have been calculated using a centred difference on the 5-day data and from these results the physics have been estimated as a residual.

In Sects. 3 and 4, we define the Warm Water Volume (WWV) as the volume of water warmer than $20^{\circ} \mathrm{C}$ within $5^{\circ}$ of latitude either side of the equator as it has been originally done in Meinen and McPhaden (2000). We choose to extend the meridional boundaries from the western coast to the eastern coast so that no zonal transport occurs within our domain. The sensitivity of the results to the choice of the isotherm used to define WWV is discussed in Sect. 5.

\subsection{Validation datasets}

The equatorial WWV calculated from the model outputs is validated against the Bureau of Meteorology Reasearch Center (BMRC) tropical Pacific subsurface temperature dataset (Smith 1995). This dataset includes XBT measurements and data from moorings of the TAO Array, from which monthly WWV timeseries are computed as by Meinen and McPhaden (2000) and made available for the period of 1980 up to present (http://www.pmel.noaa.gov/ tao/elnino/wwv/). Meinen and McPhaden (2001) also used this subsurface temperature dataset along with historical hydrographic data and FSU wind product to quantify the Ekman and geostrophic transports (see Meinen and McPhaden (2001) for further details). We compare our modelled interior meridional WWV transports to this estimate as well as to the estimate provided by Bosc and Delcroix (2008) who computed their geostrophic transports using sea level anomalies derived from the AVISO altimetry product and their Ekman transport using wind stress data derived from ERS and Quickscat satellites (see Bosc 
and Delcroix (2008) for further details). In the following section, these observational estimates are compared to the model outputs from the higher-resolution configuration (ORCA-R025).

(a) Equatorial Pacific temperature profile: Model

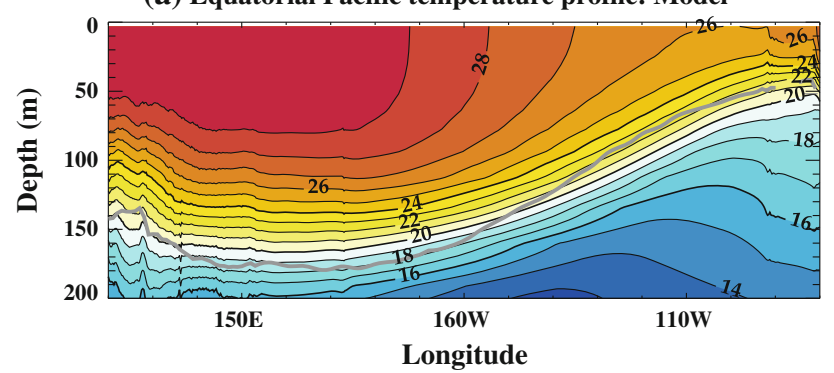

(b) Equatorial Pacific temperature profile: WOA05

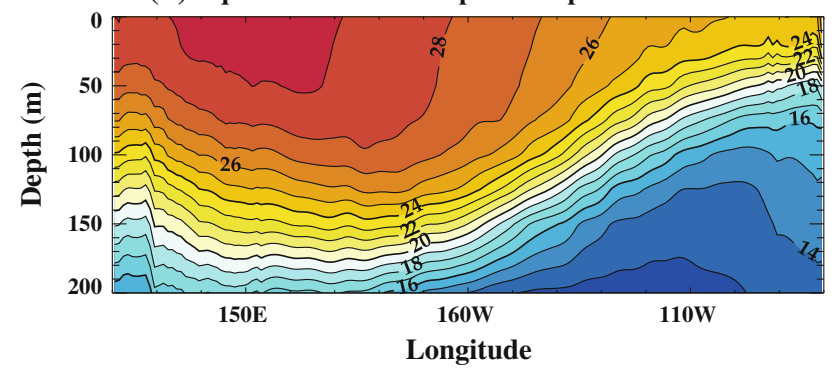

(c) Equatorial Pacific temperature profile: Model - WOA05

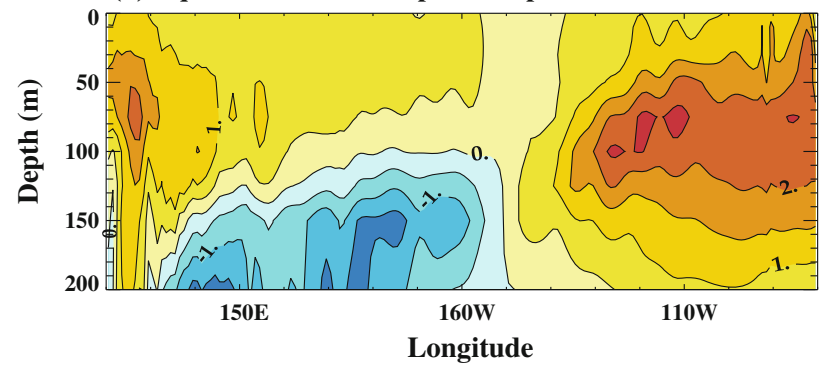

Fig. 1 Vertical section of temperature climatology in the equatorial Pacific for a ORCA025 experiment, b WOA05 dataset (Locarnini et al. 2006) and $\mathbf{c}$ the difference between the model and WOA05 datasets. The thick grey line on the upper panel displays the $20^{\circ} \mathrm{C}$ isotherm from WOA05

\section{Model validation}

The depth of the $20^{\circ} \mathrm{C}$ isotherm (a proxy for the thermocline depth) in the equatorial band is an essential parameter in the recharge-discharge oscillator theory. In the eastern Pacific, the relative influence of both turbulent heat fluxes and penetrating solar radiation on the WWV variations will strongly depend on the mean depth of the $20^{\circ} \mathrm{C}$ isotherm. A shallow thermocline is likely to enhance isothermal mass transport across the $20^{\circ} \mathrm{C}$ through enhanced mixing and penetrating solar heat flux deposition while a deep thermocline is likely to reduce this effect. We thus need to validate this variable in our model simulation. For that purpose, Fig. 1 compares the climatological thermal stratification at the equator in the model with the one from the World Ocean Atlas 2005 (WOA05, Locarnini et al. 2006). The thermal stratification above the thermocline is comparable to the observed climatology while it is too weak at depth. As far as the $20^{\circ} \mathrm{C}$ depth is concerned, the modelled equatorial depth matches the observed estimate for the equatorial mean while it is slightly overestimated east of $155^{\circ} \mathrm{W}$ and underestimated west of it (by up to $15 \mathrm{~m}$ ). These biases can be related to the eastern Pacific temperature warm bias and western Pacific temperature cold bias at depth (Fig. 1c). The potential consequence of these biases and the dependency of the results to the isotherm above which WWV is calculated will be further discussed in Sect. 5. The vertical structure of the simulated equatorial currents is also of great importance as it largely determines the characteristics of zonal transport. We thus compare our model outputs to TAO equatorial moorings. The basic structure of the observed equatorial currents is remarkably well captured by the model (Fig. 2). The modelled mean depth of the equatorial undercurrent agrees very well with the observed one in the eastern Pacific, and only underestimates its amplitude by less than 5\%. In the central and western Pacific, the modelled undercurrent is slightly shallower (by $\sim 20 \mathrm{~m}$ ) and weaker (by $\sim 5-10 \%$ ). Surface

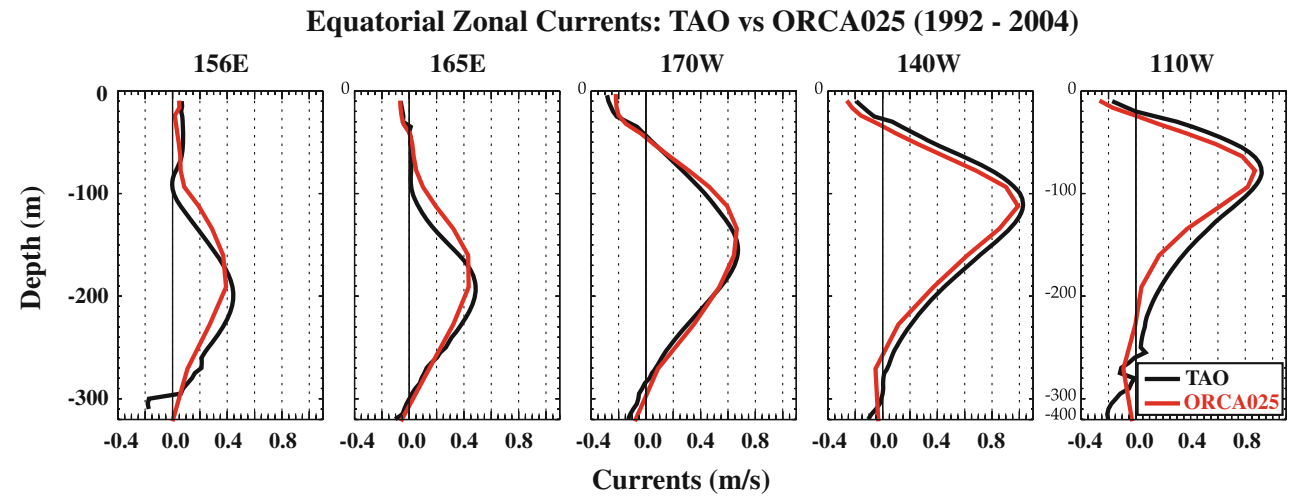

Fig. 2 Mean zonal velocity profiles for TAO data and ORCA025 at the TAO mooring locations: $156^{\circ} \mathrm{E}, 165^{\circ} \mathrm{E}, 170^{\circ} \mathrm{W}, 140^{\circ} \mathrm{W}, 110^{\circ} \mathrm{W}$ 
currents are also reasonably well reproduced with amplitude of the westward flowing south equatorial current within $20 \%$ of the observed estimate. As the structure and amplitude of simulated currents are very sensitive to the vertical mixing parametrization used, the overall good agreement with TAO data gives also confidence that mixing is reasonably well represented in the model.

The variability of the model thermocline in the tropical Pacific is inferred by applying an empirical orthogonal function (EOF) analysis on the depth of the $20^{\circ} \mathrm{C}$ isotherm (hereafter D20) as in Meinen and McPhaden (2000). The first two EOF modes explain 34 and $20 \%$ of the total variance respectively, with higher modes each representing less than $7 \%$ of the total variance (Fig. 3). The first mode represents an "east-west tilting" mode pivoting around $150^{\circ} \mathrm{W}$ while the second mode involves more a north-south tilting along an axis centred near $5^{\circ} \mathrm{N}$ coinciding with the North Equatorial Countercurrent pathway and maximum along the equator in the central and eastern Pacific. This second mode can be viewed as an equatorial "recharge-discharge" mode of warm waters in the equatorial region. The equatorial recharge-discharge mode leads the east-west tilting mode by about 8 months, consistent with the theoretical rechargedischarge oscillator of Jin (1997a). These results (EOF patterns, $\%$ of explained variance and temporal evolution) are in very good agreement with a similar analysis performed on the D20 of the BMRC reanalysis (Meinen and McPhaden 2000) and observationally derived analysis of 0-400 dbar dynamic height anomalies (Delcroix 1998) and sea level anomalies (Alory and Delcroix 2002).

WWV inferred from both the model and the BMRC reanalysis also agree very well. Over the 1980-2004 average period, they differ by less than $2 \%$ in the two datasets $\left(2.50 \cdot 10^{6} \mathrm{~km}^{3}\right.$ for the model compared to $2.46 \cdot 10^{6} \mathrm{~km}^{3}$ in observations). In agreement with a slightly deeper than observed $20^{\circ} \mathrm{C}$ isotherm in the eastern Pacific (Fig. 1), the model slightly overestimates the WWV in the eastern part of the basin by $\sim 10 \%\left(0.87 \cdot 10^{6} \mathrm{~km}^{3}\right.$ for the model compared to $0.78 \mathrm{~km}^{3}$ in observations). The modelled WWV variability in the equatorial strip, as well as in the eastern and western part of the basin on both sides of $155^{\circ} \mathrm{W}$, are then compared to the one calculated from the BMRC dataset, along with the SST in the Niño34 region (Fig. 4). Modelled WWV interannual variability closely matches the one calculated from the BMRC dataset, with correlation coefficients between WWV estimates exceeding 0.9, whether regarding total field, interannual anomalies or the seasonal cycle in the western, eastern or entire tropical Pacific.

Similarly, the SST evolution in the Niño34 box and its phase relationship with WWV on interannual time-scales are accurately reproduced by the model. Figure 5 indeed reveals that in both the model and observed estimates, the total WWV leads the ENSO cycle (and the WWV in the eastern box) with a maximum correlation $(\sim 0.65)$ at 7 months lag. This out-of-phase relationship, that constrains to the transition between ENSO events in the recharge-discharge oscillator theory proposed by Jin (1997a, b), is controlled by western Pacific WWV variability since eastern Pacific WWV varies in phase with ENSO (red curve in Fig. 5; Meinen and McPhaden 2001).

As pointed out by several observational (Meinen and McPhaden 2001; Bosc and Delcroix 2008) and model studies (Brown and Fedorov 2010), water mass exchange (a) Z20 EOF 1 Structure (Var= 34\%)

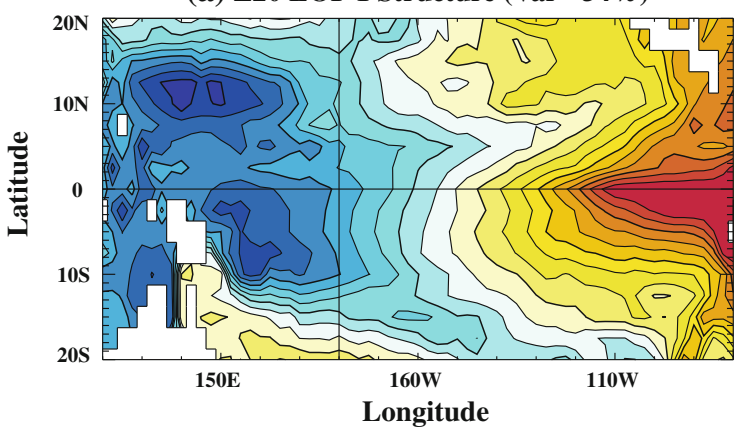

(b) Z20 EOF 2 Structure (Var $=20 \%$ )

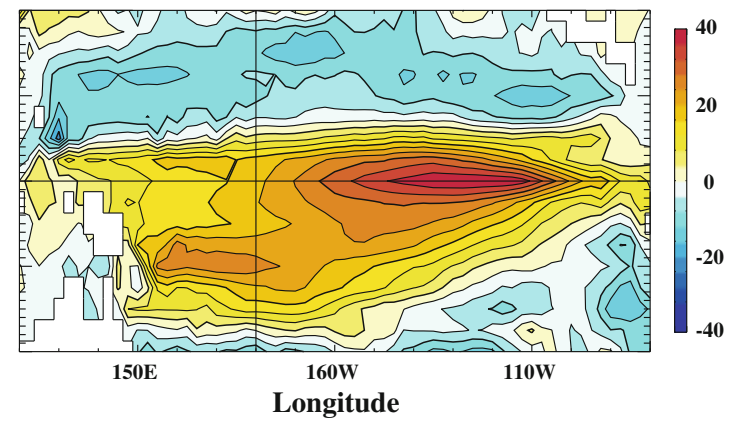

(c) Z20 EOF 1 (solid) and EOF 2 (dashed) Amplitude

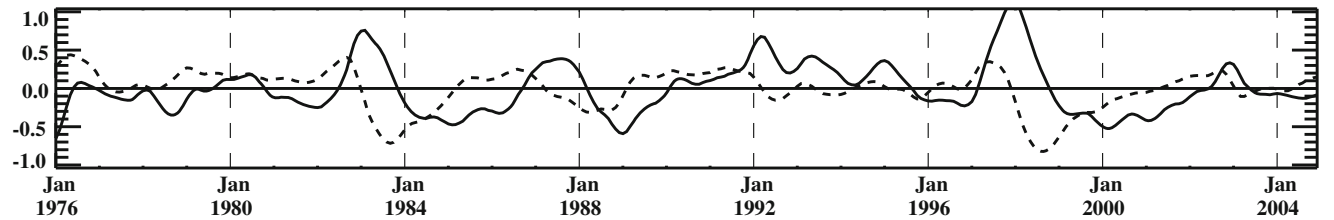

Fig. 3 a, b First two EOFs patterns of the interannual variations of the $20^{\circ} \mathrm{C}$ isotherm. c Principal components of these first two EOFs. Anomalies have been computed by removing the mean seasonal cycle and detrending the resulting time series 
(a) Niño34 SST Anomalies

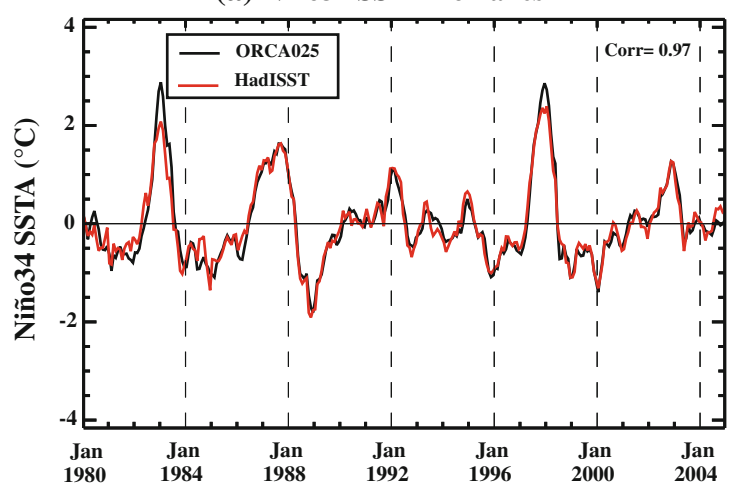

(c) Western Pacific WWV Anomalies

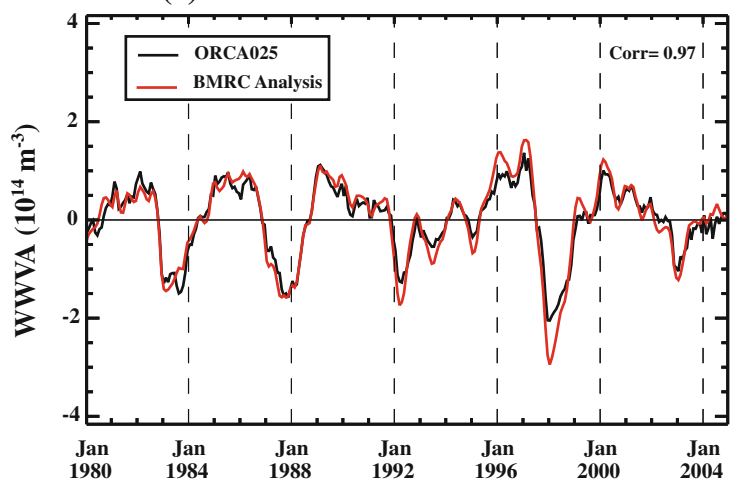

Fig. 4 Interannual anomalies of a observed and modelled SST in the Niño3.4 region, b equatorial Warm Water Volume from the model and the BMRC analysis. $\mathbf{c}, \mathbf{d}$ Same as (b) but east and west of $155^{\circ} \mathrm{W}$.

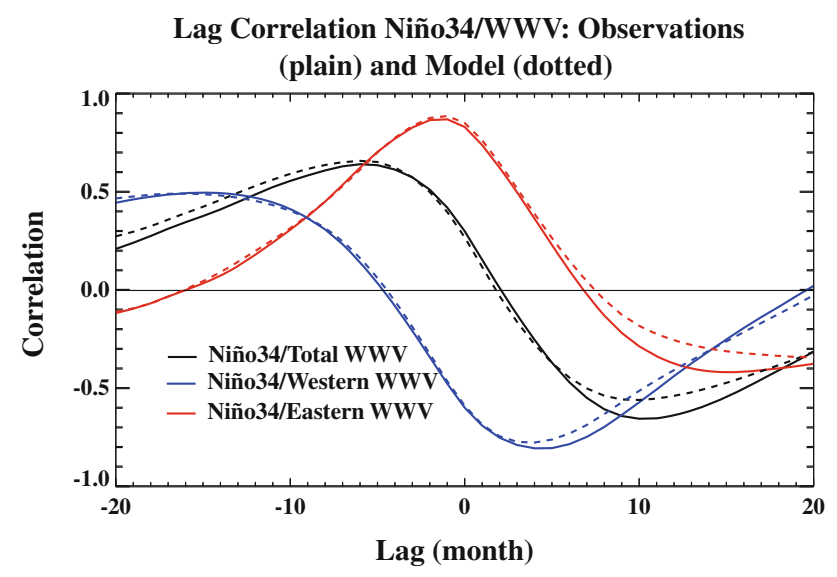

Fig. 5 Lag-correlations of interannual anomalies of Niño34 SST with anomalies of total (black), western (blue) and eastern (red) equatorial WWV for the observations (plain) and the model (dotted). Negative lags correspond to WWV leading Niño34 SST anomalies. Anomalies have been computed by removing the mean seasonal cycle and detrending the resulting time series

through the meridional boundaries is an essential contributor to the WWV interannual variations. Figure 6 hence provides a validation of the modelled meridional transport at both $5^{\circ} \mathrm{N}-5^{\circ} \mathrm{S}$ and $8^{\circ} \mathrm{N}-8^{\circ} \mathrm{S}$ boundaries to the observed estimates of total meridional transport inferred from TAO (b) Total WWV anomalies

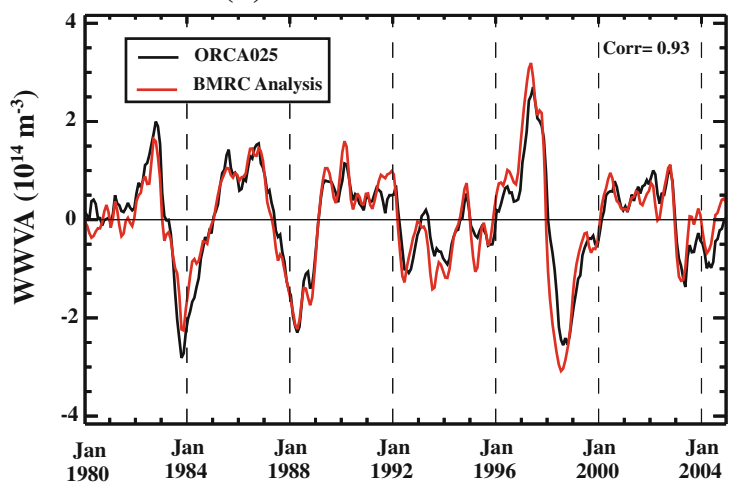

(d) Eastern Pacific WWV Anomalies

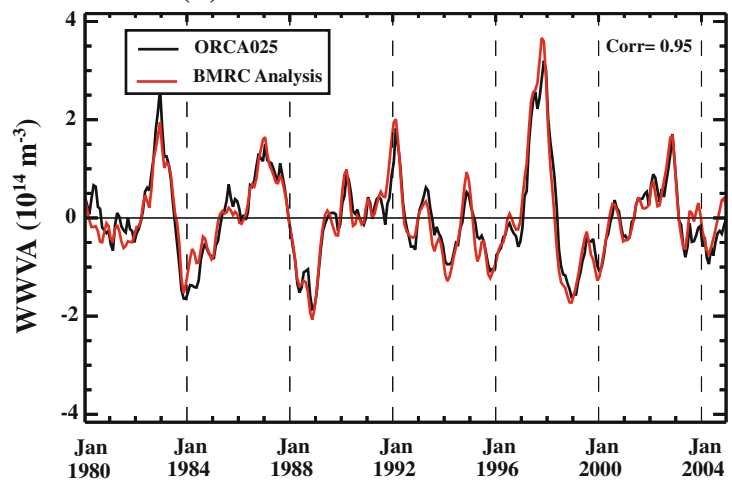

Anomalies have been computed by removing the mean seasonal cycle and detrending the resulting time series

moorings (see Meinen and McPhaden 2001) and sea-level anomalies (see Bosc and Delcroix 2008). The model is able to reproduce the main meridional interannual transport variations, its transport being within the range of both observed estimates. Correlations between the interannually filtered model transport and both observed estimates is $\sim 0.9$ over their common period.

In this simulation, the Pacific WWV, its relationship with the ENSO cycle and the meridional transport agree very well with observational estimates. In the next section, we therefore use the modelled WWV variability with some confidence to investigate the main processes controlling the WWV evolution on interannual time-scales. In the following, interannual modelled anomalies are calculated by removing the mean seasonal cycle to the raw data and applying a 16 months to 8 years band pass Hanning filter to these anomalies.

\section{WWV interannual variability}

\subsection{Diabatic versus adiabatic processes}

The modelled interannual equatorial WWV budget from 1976 to 2004 is presented in Fig. 7. Here, processes 
Fig. 6 Interannual variations of meridional WWV transport along a $5^{\circ} \mathrm{N}-5^{\circ} \mathrm{S}$ and $\mathbf{b} 8^{\circ} \mathrm{N}-8^{\circ} \mathrm{S}$ calculated for the model (black) and estimated from observations using datasets from Meinen and McPhaden (2001) (red) and Bosc and Delcroix (2008) (blue). Each data set is filtered using a 16 months low-pass Hanning filter
Fig. 7 Interannual variations over the 1976-2004 period of $\mathrm{d}(\mathrm{WWV}) / \mathrm{dt}$ (black), diabatic (red) and adiabatic processes (blue), and Niño34 SST anomalies (dotted). Units are in Sverdrup (left) and ${ }^{\circ} \mathrm{C}($ right). Interannual anomalies are calculated by removing the mean seasonal cycle and applying a 16 months to 8 years band pass Hanning filter to these anomalies (a) Interannual meridional WWV transport entering $5 \mathrm{~N}-5 \mathrm{~S}$

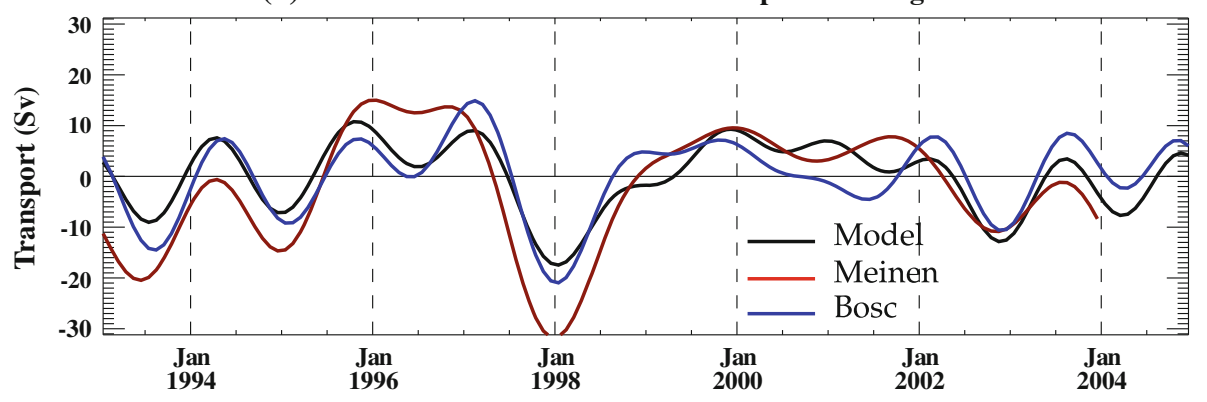

(b) Interannual meridional WWV transport entering $8 \mathrm{~N}-8 \mathrm{~S}$
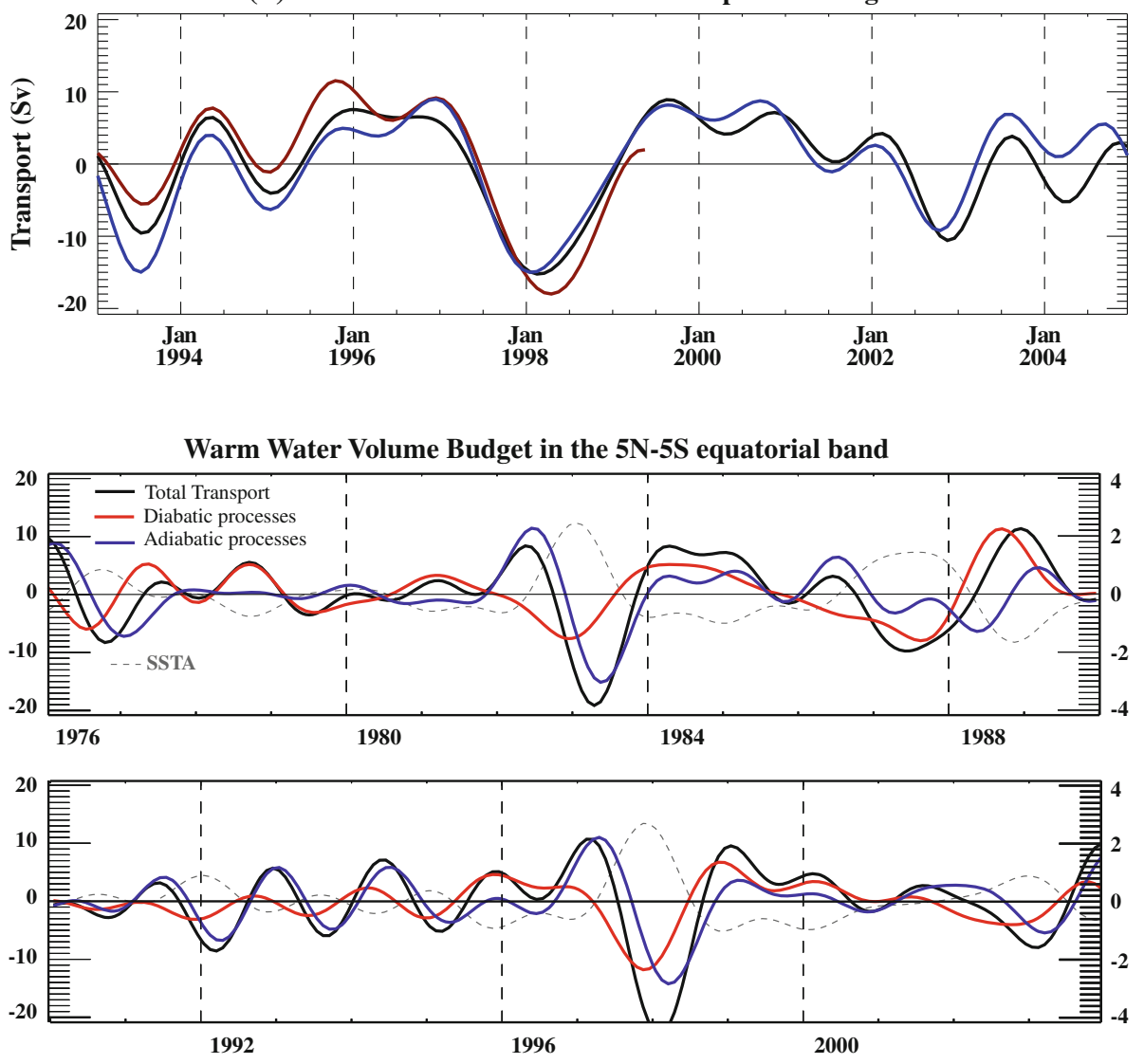

influencing the WWV evolution are split between diabatic (vertical mixing and atmospheric fluxes) and adiabatic processes (i.e. meridional transport in this study as there is no zonal transport due to the coast-to-coast extension of our northern and southern boundaries). We first discuss the case of the 1997/98 El Niño as previous studies investigating WWV interannual variations (Meinen and McPhaden 2000, 2001; Bosc and Delcroix 2008; Brown and Fedorov 2010) mainly focused their analysis on the recent period (from 1993 onwards), devoting a special attention to the evolution of the WWV during this very strong event. Figure 7 shows that the 1997/98 event is characterized by a rapid build-up of WWV, particularly strong from the mid-1996 to early 1997 , principally driven by adiabatic processes. From then, a very rapid and strong depletion of WWV occurs, with a maximum WWV change in early 1998 reaching $23 \mathrm{~Sv}$. The modelled meridional volume transport is too small in amplitude (reaching a maximum of $13 \mathrm{~Sv}$ in May 1998) and starts too late (mid-1997) to explain the observed timing and amplitude of the WWV decrease. A strong net downward transport across the $20^{\circ} \mathrm{C}$ isotherm allows to close the volume budget. An anomalously large cross-isothermal volume transports, driven by mixing and solar penetration, starts developing from early 1997, reaching a maximum amplitude of $11 \mathrm{~Sv}$ in late 1997. Similarly, a large part of the WWV build-up during the following 1998-2000 La Niña event is explained by a diabatic upward transport. These model results are consistent with the observational study of Meinen and McPhaden (2001). They estimate that only approximately half of the warm water lost during the 
Table 1 Standard deviation correlation with Niño34, correlation and regression at lag 0 with equatorial WWV changes for diabatic processes, meridional transports and equatorial WWV changes

\begin{tabular}{lllll}
\hline Variable & STD $(\mathrm{Sv})$ & COR $(\mathrm{N} 34)$ & COR (dWWV/dt) & REG $(\mathrm{dWWV} / \mathrm{dt})$ \\
\hline Volume change & 6.34 & -0.81 & 1 & 1 \\
Meridional transport & 4.54 & -0.39 & 0.81 & 0.58 \\
Diabatic processes & 3.77 & -0.88 & 0.70 & 0.42 \\
\hline
\end{tabular}

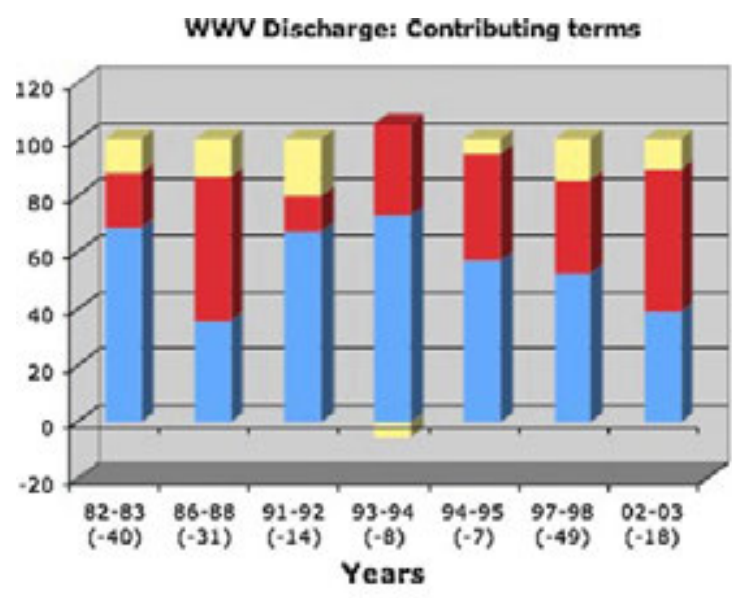

Fig. 8 Respective contributions of diabatic and adiabatic processes to the WWV build-ups and depletions over the 1976-2004 period (expressed as \%). These contributions have been calculated by integrating each of process over the duration of each discharge and

$1997 / 98$ event is accounted for by horizontal transports, while the remaining half is accounted for by vertical water mass transformations. In contrast, modelling results of Brown and Fedorov (2010) suggest that the contribution of diabatic processes to WWV evolution during this El Niño event is negligible. These contradictory results will be further discussed in Sect. 5.

The long model integration allows estimating the contributions of horizontal convergences and diathermal transports to the equatorial WWV budget on ENSO time scales for a large variety of ENSO events (El Niño/La Niña, Moderate/Strong). Over the 1976-2004 period, diabatic and adiabatic processes do show a similar amplitude, with a standard deviation of $\sim 4 \mathrm{~Sv}$ and are highly correlated with WWV changes (Table 1). Regression coefficients indicate that over the entire period, adiabatic processes contribute to about $60 \%$ of the WWV changes while diabatic processes explain the remaining part $(\sim 40 \%)$. Thus, in this model, diabatic processes in this model do play a significant role in the evolution of the WWV on interannual time scales, not only during the 1997/98 event but for the entire 1976-2004 period. The relative contribution of diabatic and adiabatic processes in WWV build-up and depletion for each ENSO event does however considerably vary from one event to

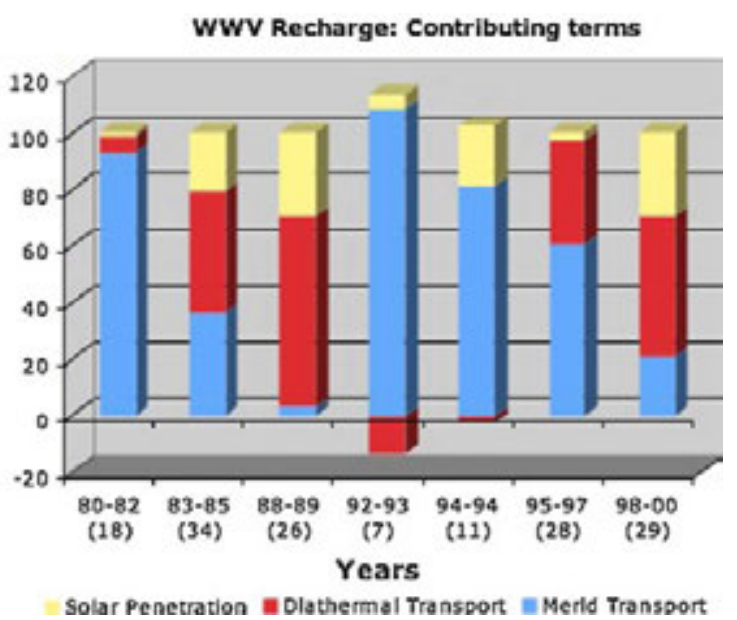

recharge. Recharge (discharge) period are defined as periods of positive (negative) dWWV/dt (as displayed on Fig. 7). The relative amplitude of recharges and discharges is shown in parenthesis (in $10^{4} \mathrm{~km}^{3}$ )

another (Fig. 8). The respective contribution of diabatic and adiabatic processes to the WWV discharge varies from $33 / 67 \%$ during the 1993 warm event to $68 / 32 \%$ during the 1986-1987 El Niño. WWV build-ups even display a stronger event-to-event variability. They are strongest and fastest during strong La Niña events, such as in 1983/85, $1988 / 89$ or $1998 / 2000$, with diabatic processes contributing to about $80 \%$ of the WWV build-up. In contrast meridional recharge dominates the build-up process $(\sim 70 \%$ of the WWV increase) during weaker La Niña events (1995/97, 1980/82) or neutral phases (1992/93, 1994/95).

\subsection{Details of adiabatic processes}

On average, meridional recharge/discharge processes control almost $60 \%$ of the WWV depletion/build-up. Figure 9 allows determining where the equatorward transport occurs along both northern and southern boundaries on ENSO time-scales. Across the northern boundary, the ENSOrelated recharge/discharge of warm waters occurs throughout much of the basin while it is mainly confined to the west of $160^{\circ} \mathrm{W}$ along the southern boundary. These findings are in agreement with the observational analysis of Meinen and McPhaden (2001) during the 1997/98 El Niño event and are inconsistent with the hypothesis of Wyrtki 


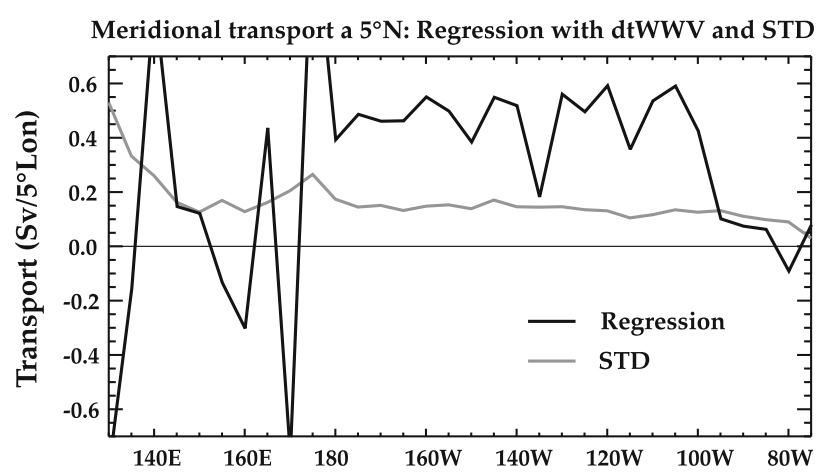

Meridional transport a $5^{\circ} \mathrm{S}$ : Regression with dtWWV and STD

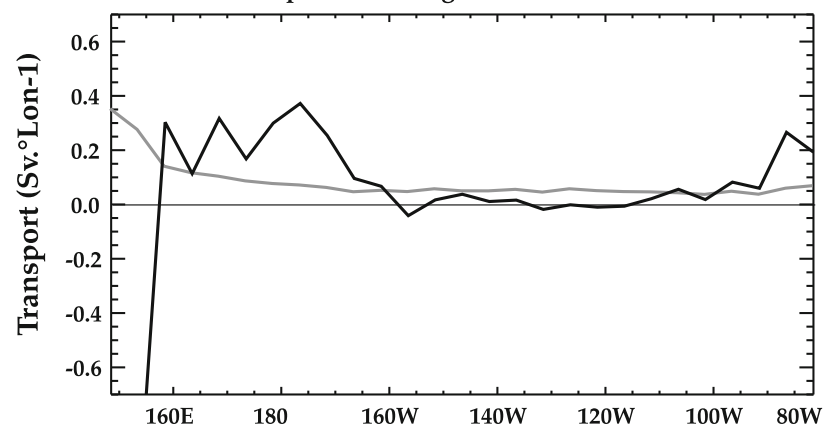

Fig. 9 Standard deviation (grey) and regression coefficient (black) of interannual variations of meridional transports at $5^{\circ} \mathrm{N}$ and $5^{\circ} \mathrm{S}$ as a function of longitude with interannual WWV changes over the 1976-2004 period. Units for STD are Sv per $5^{\circ}$ longitude

(1985) that the pathway for recharge/discharge is mainly along the west coast of the Americas. This maximum variability of meridional transport along western boundaries has also been noticed in Bosc and Delcroix (2008).

Figure 9 also highlights the considerable interannual variability of the meridional transport along the western boundaries, which opposes the interior transport especially along the southern boundary. In the following, we define western boundary transports as the meridional transports occurring west of $156^{\circ} \mathrm{E}$, interior transports being referred as the remaining. As seen in Fig. 10a and Table 2, most of the ENSO-related recharge/discharge is controlled by the northern boundary with a strong in-phase relationship between WWV changes and meridional transport through $5^{\circ} \mathrm{N}$. In contrast, transports along the southern border do show a weaker and out of phase relationship with WWV changes on ENSO time-scales, in agreement with. The interior transports at both the northern and southern boundaries are in phase with the WWV changes (Fig. 10 and Table 2). In contrast, the transport along the southwestern boundary is in phase opposition with the WWV changes and hence compensates the interior transport (Table 2). This lagged correlation is in agreement with the satellite analysis of Melet et al. (2010) where meridional transports in the Solomon Sea are also shown to be in phase opposition with WWV changes on ENSO timescales. Such (a) Lag regression of the $\mathrm{dtWWV}$ and total meridional transport

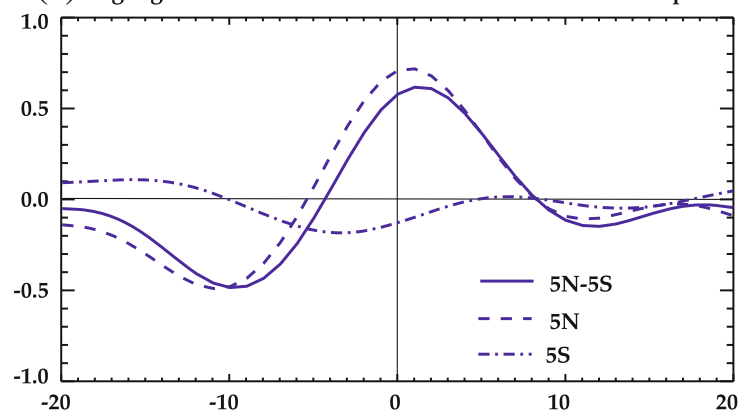

(b) Lag regression of the $\mathrm{dtWWV}$ and meridional transport in the interior

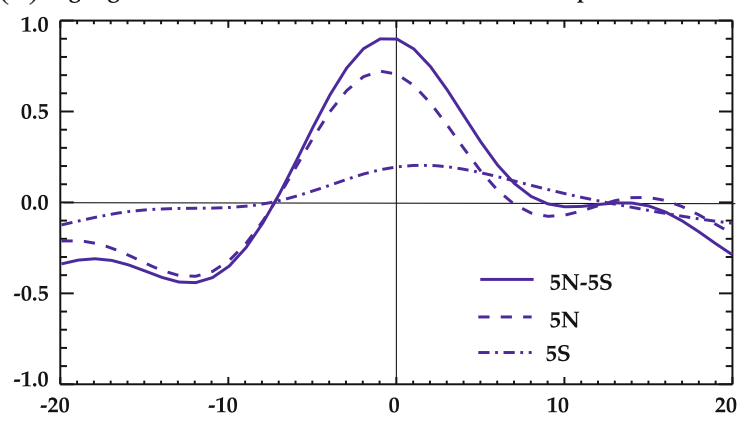

(c) Lag regression of the $\mathrm{dtWWV}$ and meridional transport at the boundaries

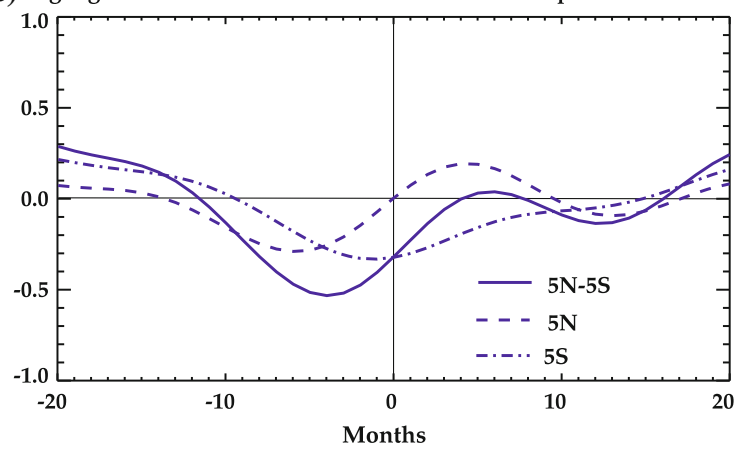

Fig. 10 a Lag-regressions of interannual variations of $\mathrm{dWWV} / \mathrm{dt}$ with total (boundary and interior) meridonal transports at $5^{\circ} \mathrm{N}, 5^{\circ} \mathrm{S}$ and $5^{\circ} \mathrm{N}-5^{\circ} \mathrm{S}$. b, c Same as (a) but for meridional transports in the interior and at the western boundaries (west of $156^{\circ} \mathrm{E}$ ) respectively. Negative lags correspond to transports leading WWV changes

compensation does not hold in the northern hemisphere, where the boundary transport is in quadrature with the WWV changes and the interior transports, lagging them by about 5 months. This lack of compensation combined with the larger zonal extent of the interior transport along the northern boundary as compared to the southern boundary explains the stronger impact of the northern hemisphere on the recharge-discharge of the equatorial WWV. The modelling study of Ishida et al. (2008) also discuss this northsouth asymmetry in the western boundary transport, with interior transport compensation in the southern hemisphere but not in the northern hemisphere. They attributed the existing lag between the western boundary and interior transport in the northern hemisphere to the negative wind 
Table 2 Standard deviation, correlation with Niño34 SST anomalies and correlation and regression at lag 0 with equatorial WWV changes for interannual anomalies of total, boundary and interior transports at $5^{\circ} \mathrm{N}, 5^{\circ} \mathrm{S}$ and $5^{\circ} \mathrm{N}-5^{\circ} \mathrm{S}$
Table 3 Standard deviation, correlation with Niño34 SST anomalies and correlation and regression at lag 0 with equatorial WWV changes for interannual variations of diabatic processes (diathermal mixing and solar penetration)

\begin{tabular}{lllll}
\hline Variable & STD & $\begin{array}{l}\text { COR } \\
(\mathrm{N} 34)\end{array}$ & $\begin{array}{l}\text { COR } \\
(\mathrm{dWWV} / \mathrm{dt})\end{array}$ & $\begin{array}{l}\text { REG } \\
(\mathrm{dWWV} / \mathrm{dt})\end{array}$ \\
\hline Volume change & 6.34 & -0.81 & 1 & 1 \\
Total transport $5^{\circ} \mathrm{N}-5^{\circ} \mathrm{S}$ & 4.54 & -0.39 & 0.81 & 0.58 \\
Interior transport $5^{\circ} \mathrm{N}-5^{\circ} \mathrm{S}$ & 6.88 & -0.69 & 0.85 & 0.89 \\
Boundary transport $5^{\circ} \mathrm{N}-5^{\circ} \mathrm{S}$ & 5.64 & 0.64 & -0.51 & -0.32 \\
Total transport $5^{\circ} \mathrm{N}$ & 5.56 & -0.53 & 0.77 & 0.70 \\
Interior transport $5^{\circ} \mathrm{N}$ & 5.45 & -0.65 & 0.81 & 0.70 \\
Boundary transport $5^{\circ} \mathrm{N}$ & 2.99 & 0.34 & $\mathrm{NS}$ & $\mathrm{NS}$ \\
Total transport $5^{\circ} \mathrm{S}$ & 2.94 & 0.49 & -0.29 & -0.13 \\
Interior transport $5^{\circ} \mathrm{S}$ & 3.48 & -0.31 & 0.39 & 0.19 \\
Boundary transport $5^{\circ} \mathrm{S}$ & 3.43 & 0.74 & -0.64 & -0.32 \\
\hline
\end{tabular}

\begin{tabular}{lllll}
\hline Variable & STD $(\mathrm{Sv})$ & COR $(\mathrm{N} 34)$ & COR $(\mathrm{dWWV} / \mathrm{dt})$ & REG $(\mathrm{dWWV} / \mathrm{dt})$ \\
\hline Volume change & 6.34 & -0.81 & 1 & 1 \\
Diabatic processes & 3.77 & -0.88 & 0.70 & 0.42 \\
Diabatic processes East & 3.62 & -0.85 & 0.64 & 0.37 \\
Diabatic processes West & 0.79 & -0.31 & 0.44 & 0.05 \\
Diathermal mixing & 2.62 & -0.79 & 0.70 & 0.29 \\
Solar penetration & 1.31 & -0.87 & 0.64 & 0.13 \\
\hline
\end{tabular}

stress curl in the north equatorial Pacific that develops after the mature state of El Niño. Accounting for the interior transports alone allows to retrieve a large part of the WWV variability (regression between $5^{\circ} \mathrm{N}-5^{\circ} \mathrm{S}$ interior transports and WWV changes of $\sim 0.9$ ), while accounting also for the transports at the boundaries reduce by $\sim 30 \%$ the transports contribution to the WWV changes.

\subsection{Details of diabatic processes}

Our analysis suggests that diabatic processes are first order contributors to ENSO-related WWV variations, contributing as much as $80 \%$ to the WWV build-up during strong La Niña events (see Sect. 3.1). As discussed in Sect. 2, two different diabatic processes can influence diathermal volume transports: vertical oceanic mixing and the penetrative solar flux divergence. Table 3 suggests that both components contribute significantly to diabatic heating, with vertical mixing accounting for about two-third of the signal and solar penetration explaining the remaining.

As shown on Table 3, these diabatic processes are mainly active in the eastern part of the basin while their variations are fairly weak over the warm-pool region. Both components of diabatic heating show a strong out-of-phase relationship with Niño34 SST anomalies, while they lead by $3-4$ months the WWV changes (Fig. 11). These phase relations and geographical distribution of the modelled diathermal transport are consistent with expectations based on ENSO dynamics as the contribution of both solar heating and physics strongly depends on the vertical thermal structure. On a climatological basis, vertical mixing acts to form warm waters in the eastern Pacific. During an El Niño event, the thermocline in the eastern Pacific deepens, moving the $20^{\circ} \mathrm{C}$ isotherm away from the mechanic energy input by surface wind stress. In addition, trade winds weaken, reducing the available amount of energy for mixing. Equatorial upwelling and stratification are reduced, contributing to the decreased intensity of the turbulent heat fluxes, diathermal transport and hence WWV. In contrast, during La Niña events, the anomalously shallow thermocline, stronger wind and stratification favour enhanced vertical mixing of heat and mass across the $20^{\circ} \mathrm{C}$ and hence WWV formation by diathermal transport.

A similar argument explains the variations of diabatic heating through solar forcing. With the deepening of the thermocline in the eastern Pacific during an El Niño event, an exponentially smaller part of the solar radiation will reach the $20^{\circ} \mathrm{C}$ isotherm. Since the convergence of an exponential is an exponential, the formation of WWV by penetrating solar forcing will consequently decrease nearly exponentially with isotherm depth. Therefore during El Niño events, the anomalously small formation of WWV by solar forcing in the east will contribute to the depletion of equatorial WWV. A reverse argument allows explaining the build-up of WWV by penetrating solar forcing during La Niña events, during which the thermocline in the eastern Pacific considerably shoals. 
(a) Lag regression of the dtWWV and diabatic processes

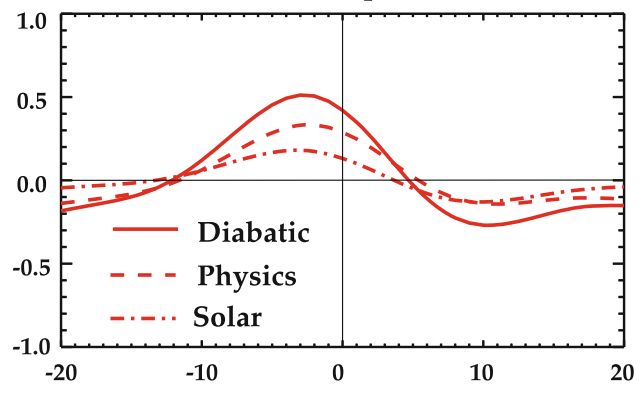

Fig. 11 a Lag-regression of interannual variations of WWV with total diabatic processes (plain), vertical mixing (dotted) and solar petration (dotted-dashed). b Lag-correlation of interannual variations of Niño34 SST interannual anomalies with total diabatic processes

Our results suggest that this diabatic WWV formation/ depletion is particularly efficient during strong La Niña events. During the strongest La Niña events (1983/85, $1988 / 89$ and 1998/2000), the thermocline is brought up close to the surface in the eastern Pacific allowing these diabatic processes to account for more than $70 \%$ to the WWV recharge, $1 / 3$ being related to solar penetration and $2 / 3$ to vertical mixing processes (Fig. 8). In contrast, buildups occurring during almost neutral conditions in the eastern Pacific (80-82, 92-93) do not show a significant contribution of these diabatic processes.

\section{Discussion}

\subsection{Comparison with previous studies}

Our analysis underlines the important role of diabatic exchanges through the $20^{\circ} \mathrm{C}$ isotherm in the modelled WWV budget. This result agrees with the observational studies of Meinen and McPhaden (2001) and Clarke et al. (2007). It however differs from the results of Bosc and Delcroix (2008) and the modelling study of Brown and Fedorov (2010), which both suggest that diathermal transport only marginally contributes to WWV evolution. The discrepancy with Bosc and Delcroix (2008) may arise from the fact that they suggested the ENSO-related western boundary current variations to be marginal contributors to the WWV evolution. This is in contradiction with the results of Clarke et al. (2007) and Ishida et al. (2008), who have shown, from observations and model outputs respectively, that western boundary layer transport cannot be neglected and oppose the interior transports. An inaccurate estimation of the western boundary currents variations could have led Bosc and Delcroix (2008) to overestimate the role of meridional transport, hence underestimating the role of physics. (b) Lag correlation of Niño34 and diabatic processes

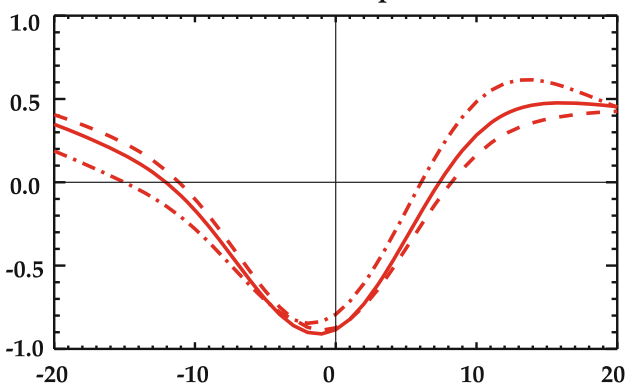

(plain), vertical mixing (dotted) and solar petration (dotted-dashed). Negative values of the lag correspond to diabatic processes leading WWV changes/Niño34 SST anomalies

Several reasons may explain the discrepancy between our modelling results and those of Brown and Fedorov (2010). First, they did not account for the solar penetrative flux in the diathermal transport calculation. Discrepancies between the two studies could also arise from mean state differences. In Brown and Fedorov (2010), the isopycnal defining the lower boundary of the WWV is about $30 \mathrm{~m}$ deeper in the eastern Pacific than the $20^{\circ} \mathrm{C}$ in the observations (see their Fig. 1) while this overestimation is only of about $10-15 \mathrm{~m}$ in the experiment analysed in this study. This probably results in an underestimation of the role of vertical mixing, as this process is most active close to the surface.

Sensitivity of the results to the model formulation (resolution, mixing parametrisation,...) and setup (initial state, forcing) could also explain some of these differences. For instance, MOM3 and NEMO use different vertical mixing schemes and hence compute diathermal transports differently. In an attempt to evaluate the sensitivity of our results to the model formulation, the WWV budget has also been performed on lower horizontal resolution experiments ( $2^{\circ}$ and $12^{\circ}$; Penduff et al. 2010). On ENSO timescales, the results do not appear to to be strongly sensitive to the resolution used, with a role of vertical mixing, solar penetration, boundary transport and interior transport very similar between experiments (see Table 4). This is an additional reassurance that our results are robust.

\subsection{Sensitivity to isotherm choice}

WWV is generally defined as the volume of water warmer than $20^{\circ} \mathrm{C}$ within $5^{\circ}$ of latitude on either side of the equator. The choice of the $20^{\circ} \mathrm{C}$ isotherm relies on the fact that it is a good proxy for the equatorial Pacific thermocline depth in the observations. In a model study, the $20^{\circ} \mathrm{C}$ isotherm is not necessarily a good proxy for the thermocline depth owing to biases in the simulated vertical 
Table 4 Regression coefficients at lag 0 for interannual variations of diabatic and adiabiatic processes with equatorial WWV changes for different three experiments differing by their horizontal resolution

\begin{tabular}{lccc}
\hline Variable & ORCA025 & ORCA05 & ORCA2 \\
\hline Diabatic processes & 0.42 & 0.40 & 0.37 \\
Diathermal mixing & 0.29 & 0.27 & 0.25 \\
Solar penetration & 0.13 & 0.13 & 0.12 \\
Adiabatic processes & 0.58 & 0.60 & 0.63 \\
Interior transport & 0.89 & 0.99 & 0.88 \\
Boundary transport & -0.32 & -0.39 & -0.25 \\
\hline
\end{tabular}

structure. In fact, in the eastern Pacific, where diabatic processes are the most important, the $21 / 22^{\circ} \mathrm{C}$ isotherms in our experiment are likely to be a better proxy of the model thermocline and better matches the observed depth of the $20^{\circ} \mathrm{C}$ in the observations (Fig. 1). There is hence a need to test the sensitivity of our results to the choice of the isotherm above which WWV is calculated.

The relative influence of diabatic and adiabatic processes on changes in WWV calculated for different isotherms $\left(16-24^{\circ} \mathrm{C}\right)$ is illustrated in Fig. 12. As expected, the relative influence of diabatic processes (atmospheric flux + vertical mixing) on WWV changes decreases with depth, ranging from more than $50 \%$ above the $22^{\circ} \mathrm{C}$ isotherm to less than $20 \%$ for the $16^{\circ} \mathrm{C}$ isotherm. Indeed, diabatic processes are mainly active in the near surface layers where wind energy and penetrative solar forcing are available. The relative contribution of penetrative solar flux to WWV evolution strongly increases from the $20^{\circ} \mathrm{C}$ and

\section{Dependency to the isotherm}

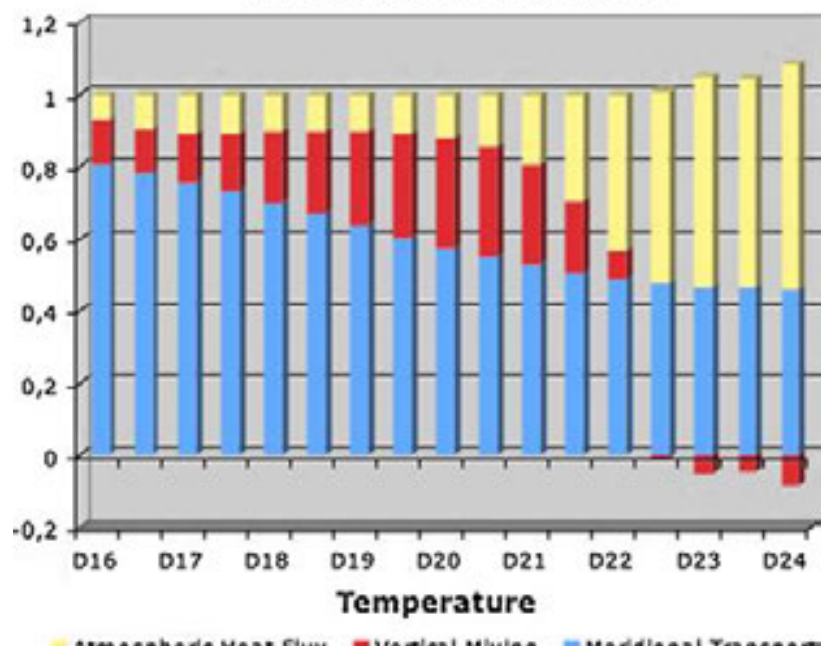

Fig. 12 Respective contribution of diabatic and adiabatic processes in WWV interannual variations as a function of the isotherm chosen to calculate WWV. Contributions are estimated by calculating the lag-0 regressions coefficient for each process with respect to dWWV/ dt interannual anomalies dominate the budget above $22^{\circ} \mathrm{C}$. The strongest contribution of vertical mixing to WWV discharge occur for isotherms between 22 and $18^{\circ} \mathrm{C}$. For isotherms warmer than $22^{\circ} \mathrm{C}$, the influence of mixing is rather weak and tends to oppose WWV changes. For isotherms within the range of the thermocline depth (between 19 and $22^{\circ} \mathrm{C}$; see Fig. 2), the respective contributions of diabatic processes (mixing + atmospheric fluxes) and adiabatic processes (meridional transport) remain however relatively stable, strengthening the robustness of our results.

\section{Summary and conclusions}

\subsection{Summary}

Interannual variations of equatorial Pacific warm water volume (WWV, defined as the volume of water above $20^{\circ} \mathrm{C}$ between $5^{\circ} \mathrm{N}$ and $5^{\circ} \mathrm{S}$ ) are known to be critical for ENSO prediction (e.g. Izumo et al. 2010). In this study, we investigated the mechanisms responsible for WWV interannual variations in a $14^{\circ}$ OGCM experiment. By applying a diagnostic first developed by Walin (1982) and extended by Iudicone et al. (2008) to model outputs, the respective roles of adiabatic processes (interior and western boundary transports) and diabatic processes (diathermal transports induced by vertical mixing and penetrative solar flux divergence) have been quantified. The good agreement of the model with observational estimates in terms of mean equatorial temperature, mean zonal currents along the equator, WWV variability and meridional transports allows us to draw conclusions on processes acting in the real world with some confidence.

Over the 1976-2004 period, adiabatic processes contribute to about $60 \%$ of the WWV changes, with diabatic processes explaining the remaining part. Figure 13 proposes a simplified sketch of the main processes controlling WWV evolution during the different ENSO phases. Interior meridional transports are in phase with WWV recharge, but are partially compensated by western boundary transports that act to reduce total transport contribution to WWV changes by $30 \%$. This is especially true in the southern hemisphere where interior and boundary transports are out of phase and tend to cancel each other. In the northern hemisphere, interior and boundary transports are almost in quadrature. This lack of compensation combined with the larger zonal extent of the interior transport along the northern boundary explains the stronger influence of meridional exchange in the northern hemisphere onto WWV changes. Our results reveal that diabatic processes are important contributors to the WWV budget and mainly act in the eastern equatorial Pacific, leading WWV changes by half a year. While previous studies attributed diabatic 

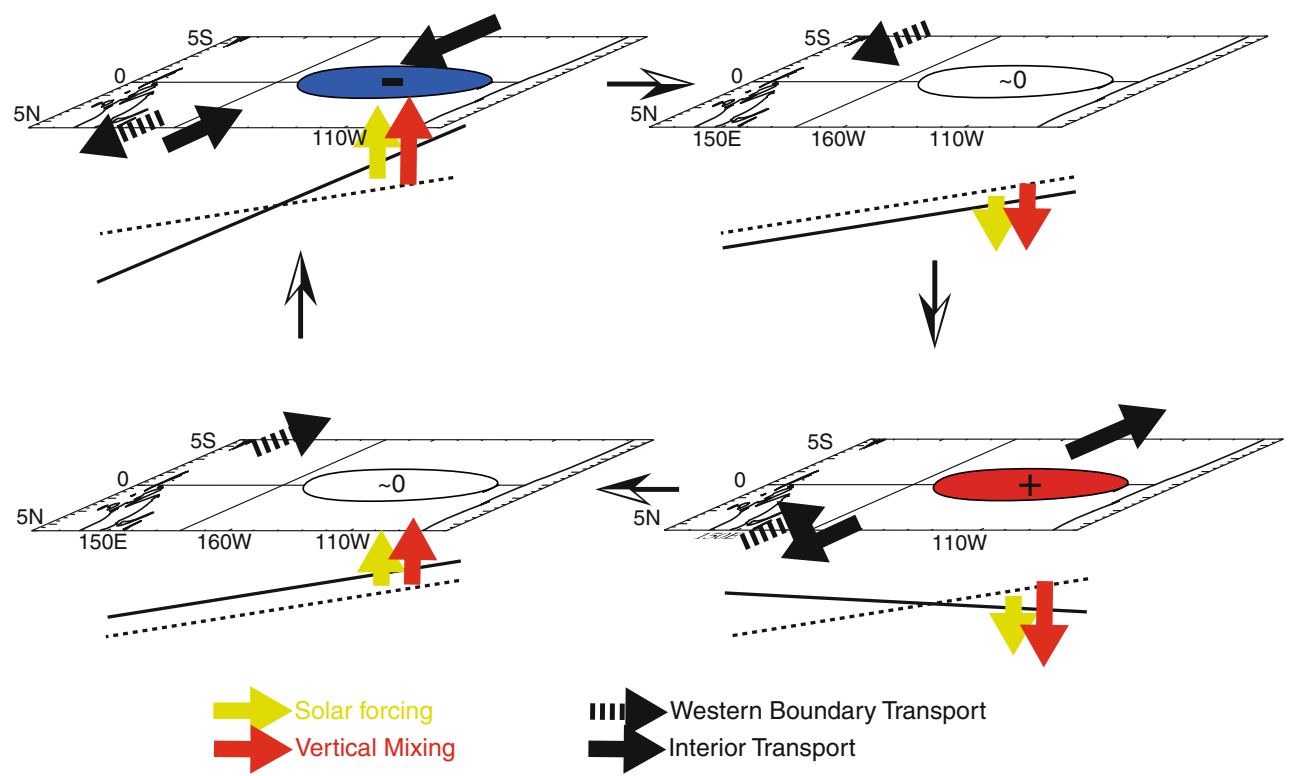

Fig. 13 Schematic of the respective contribution of diabatic and adiabatic processes to the WWV evolution during the ENSO cycle in the equatorial band. The plain and dashed thick lines indicate the interannual and climatological depth of the thermocline. Ellipses indicate the sign of the SST anomalies in the equatorial Pacific (i.e.

WWV formations/depletions entirely to diathermal transport through vertical mixing, we show that about one-third of the diabatic transport variability is associated with the penetrative solar flux.

Our extended period of study (1979-2004) also allows us to highlight large variations in the respective contribution of diabatic and adiabatic processes during build-ups/ depletions from event to event. The WWV build-up during neutral ENSO phases (e.g. 1980-1982) is almost entirely controlled by meridional recharge, providing a textbook example for the recharge/discharge oscillator theory. During the strongest La Niña events (1984, 1988, 1999), however, diabatic processes are particularly active and contribute to more than $70 \%$ of the WWV buildup, with heating by penetrative solar fluxes explaining as much as $30 \%$ of the total build-up due to a very shallow thermocline in the eastern Pacific. These results are consistent with expectations based on simple ENSO physics: during La Niña events, the anomalously shallow thermocline favours both enhanced vertical mixing of heat and mass across the $20^{\circ} \mathrm{C}$ and penetrative solar flux heating at the $20^{\circ} \mathrm{C}$ level hence resulting in increased WWV formation. The opposite occurs during El Niño events.

\subsection{Conclusions}

This study therefore suggests that, in addition to interior meridional transport, both diabatic processes and western boundary currents act to modulate WWV variations on the phase of the ENSO cycle). Yellow and red arrows respectively indicate the contribution of penetrating solar flux and vertical mixing to WWV evolution (diabatic processes). Plain and dashed black arrows respectively indicate the contribution of interior and western boundary transport to WWV evolution (adiabatic processes)

ENSO time-scale. The representation of diabatic processes is likely to depend on the mixing parametrization scheme used. Analysis of other OGCMs solutions with different vertical physics is required to assess the robustness of the present results. The penetrative solar flux has been for the first time identified as a significant contributor to WWV evolution and a more careful parameterization of this process is also required to provide a better quantitative estimate of its oceanic influence. Uncertainties existing in the surface shortwave estimations are likely to result in uncertainties in the penetrative solar flux contribution. In addition, light penetration is supposed to be independent of the visible light wavelength and of the particulate load of seawater in our experiments. However, chlorophyll is known to modify vertical distribution of radiant heating and its variability has been suggested to influence the ENSO-related surface layer heat budget (Strutton and Chavez 2004). Accounting for the influence of biology on solar penetrative forcing in our model experiments could hence improve and ascertain our conclusions on the processes influencing the WWV budget in the real world.

This study also advocates for a better understanding of the main processes and mechanisms controlling western boundary currents variations on ENSO time-scales. These currents are shown here to partially compensate interior transport. In the southern hemisphere, interior and boundary transports are out of phase while in the northern hemisphere, interior and boundary transports are almost in quadrature. A careful examination of the mechanisms 
controlling these phase relationship is beyond the scope of this paper but will be conducted in a further study. The lack of sufficient long-term in situ observations within the western boundary currents does not allow assessing the model ability in reproducing these interannual variations. International programs such as the Southwest Pacific Ocean Circulation and Climate Experiment (SPICE; Ganachaud et al. 2008) and the Northwestern Pacific Ocean Circulation and Climate Experiment (NPOCE; Wang and Dunxin 2010) will allow giving new insights about the role of western boundary currents on ENSO in observations.

The importance of diabatic processes and boundary transports and their different phase relationship with regard to WWV changes could modulate the simple picture brought by the recharge-discharge oscillator theory (Jin 1997a, b), that only account for interior meridional transport to explain WWV evolution. The varying contribution of diabatic processes during the various phases of ENSO (e.g. stronger during strong La Niñas) may also explain some of the asymmetries between El Niño and La Niña. This suggest that, in the attempt to tackle the differences found in the simulated ENSO statistics of coupled general circulation models, the representation of these processes and their respective contributions to WWV changes should be evaluated.

Acknowledgments ML would like to thank C. Meinen and C. Bosc for making their observed meridional transport estimates available as well as M. McPhaden and F. F. Jin for valuable comments and discussions on this work. The authors would also like to thank the two anonymous reviewers of this manuscript and acknowledge the DRAKKAR project (http://www-meom.hmg.inpg.fr/Web/Projets/ DRAKKAR/) for providing the oceanic simulations and the TOGA TAO Project Office for making the mooring data easily available.

\section{References}

Alory G, Delcroix T (2002) Interannual sea level changes and associated mass transports in the tropical Pacific from TOPEX/ Poseidon data and linear model results (1964-1999). J Geophys Res 107. doi:10.1029/2001JC001067

Barnier B et al (2006) Impact of partial steps and momentum advection schemes in a global ocean circulation model at eddyadmitting resolution. Ocean Dyn 56:543-567. doi:10.1007/ s10236-009-0180-y

Bentamy A, Grimas N, Quilfen Y (1999) Validation of the gridded weekly and monthly wind fields calculated from ERS-1 scatterometer wind observations. Global Atmos Ocean Syst 6:373-396

Blanke B, Delecluse P (1993) Variability of the tropical Atlantic ocean simulated by a general circulation model with two different mixed layer physics. J Phys Oceanogr 23:1363-1388

Bosc C, Delcroix T (2008) Observed equatorial Rossby waves and ENSO-related warm water volume changes in the equatorial Pacific Ocean. J Geophys Res-Oceans 113(C06003). doi: 10.1029/2007JC004613

Brodeau L, Barnier B, Penduff T, Treguier AM, Gulev S (2010) An ERA-40 based atmospheric forcing for global ocean circulation models. Ocean Model 31:88-104. doi:10.1016/j.ocemod.2009. 10.005

Brown J, Fedorov A (2010) Estimating the diapycnal transport contribution to warm water volume variations in the tropical Pacific ocean. J Clim 23:221-237. doi:10.1175/2009JCLI2347.1

Cane M, Zebiak SE (1985) A theory for El Niño and the southern oscillation. Science 228:1084-1087

Clarke AJ, Van Gorder S, Colantuono G (2007) Wind stress Curl and ENSO discharge/recharge in the equatorial Pacific. J Phys Oceanogr 37:1077-1091

Collins M, An S-I, Cai W, Ganachaud A, Guilyardi E, Jin F-F, Jochum M, Lengaigne M, Power S, Timmermann A, Vecchi G, Wittenberg A (2010) The impact of global warming on the tropical Pacific and El Niño. Nat Geosci 3:391-397. doi: $10.1038 /$ ngeo868

Cravatte S, Madec G, Izumo T, Menkes C, Bozec A (2008) Progress in the 3-D circulation of the eastern equatorial Pacific in a climate ocean model. Ocean Model 17:28-48. doi:10.1016/j. ocemod.2006.11.003

Delcroix T (1998) Observed surface oceanic and atmospheric variability in the tropical Pacific at seasonal and ENSO time scales: a tentative overview. J Geophys Res 103:18611-18633

Fichefet T, Maqueda MM (1997) Sensitivity of a global sea ice model to the treatment of ice thermo-dynamics and dynamics. J Geophys Res 102:609-646

Ganachaud A et al (2008) Southwest Pacific ocean circulation and climate experiment. Part II. Implementation plan. NOAA OAR special report/international CLIVAR project office, CLIVAR publication series no. 133

Griffies SM et al (2009) Coordinated Ocean-ice reference experiments (COREs). Ocean Model 26(1-2):1-46. doi:10.1016/j. ocemod.2008.08.007

Ishida A, Kashino Y, Hosoda S, Ando K (2008) North-south asymmetry of warm water volume transport related with El Niño variability. Geophys Res Lett 35:L18612. doi: 10.1029/2008GL034858

Iudicone D, Madec G, McDougall T (2008) Water-mass transformations in a neutral density framework and the key role of light penetration. J Phys Oceanogr 38:1357-1376

Izumo T, Vialard J, Lengaigne M, de Boyer Montégut C, Behera SK, Luo JJ, Cravatte S, Masson S, Yamagata T (2010) Influence of the Indian ocean dipole on following year's El Niño. Nat Geosci 3:168-172

Jackett DR, McDougall TJ (1995) Minimal adjustment of hydrographic data to achieve static stability. J Atmos Ocean Tech 12:381-389

Jerlov NG (1968) Optical oceanography. Elsevier, London

Jin FF (1997a) An equatorial ocean recharge paradigm for ENSO. Part I: conceptual model. J Atmos Sci 54:811-829

Jin FF (1997b) An equatorial ocean recharge paradigm for ENSO. Part II: a stripped-down coupled model. J Atmos Sci 54:830-847

Le Sommer J, Penduff T, Theetten S, Madec G, Barnier B (2009) How momentum advection schemes affect current-topography interactions at eddy permitting resolution. Ocean Model 29(1):1-14. doi:10.1016/j.ocemod.2008.11.007

Lengaigne M, Madec G, Menkes C, Alory G (2003) The impact of isopycnal mixing on the tropical ocean circulation. J Geophys Res 108. doi: 10.1029/2002JC001704

Lengaigne M, Boulanger JP, Menkes C, Spencer H (2006) Influence of the seasonal cycle on the termination of El Nino events in a coupled general circulation model. J Clim 19:1850-1868. doi: 10.1175/JCLI3706.1

Lengaigne M, Menkes C, Aumont O, Gorgues T, Bopp L, André JM, Madec G (2007) Influence of the oceanic biology on the tropical Pacific climate in a coupled general circulation model. Clim Dyn. doi:10.1007/s00382-006-0200-2 
Locarnini RA, Mishonov AV, Antonov JI, Boyer TP, Garcia HE (2006) World Ocean Atlas 2005, Volume 1: Temperature. In: Levitus S (ed). NOAA Atlas NESDIS 61, US Government Printing Office, Washington, D.C., $182 \mathrm{pp}$

Madec G (2008) "NEMO ocean engine". Note du Pole de modélisation, Institut Pierre-Simon Laplace (IPSL), France, No 27 ISSN No 1288-1619

McPhaden MJ, Zebiak SE, Glantz MH (2006) ENSO as an integrating concept in earth science. Science 314:1740. doi:10.1126/science. 1132588.

McPhaden MJ, Zhang X, Hendon HH, Wheeler MC (2006b) Large scale dynamics and MJO forcing of ENSO variability. Geophys Res Lett 33:L16702

Meinen CS, McPhaden MJ (2000) Observations of warm water volume changes in the equatorial Pacific and their relationship to El Nino and La Nina. J Clim 13:3551-3559

Meinen CS, McPhaden MJ (2001) Interannual variability in warm water volume transports in the equatorial Pacific during 1993-99. J Phys Oceanogr 31:1324-1345

Melet A, Gourdeau L, Verron J (2010) Variability in Solomon Sea circulation derived from altimeter sea level data. Ocean Dyn. doi:10.1007/s10236-010-0302-6

Paulson CA, Simpson JJ (1977) Irradiance measurements in the upper ocean. J Phys Oceanogr 7:952-956

Penduff T, Le Sommer J, Barnier B, Treguier A-M, Molines J-M, Madec G (2007) : Influence of numerical schemes on currenttopography interactions in $1 / 4^{\circ}$ global ocean simulations. Ocean Sci 3(4):491-528

Penduff T, Juza M, Brodeau L, Smith GC, Barnier B, Molines J-M, Treguier A-M, Madec G (2010) Impact of global ocean model resolution on sea-level variability with emphasis on interannual time scales. Ocean Sci 6:269-284

Roullet G, Madec G (2000) Salt conservation, free surface and varying volume: a new formulation for Ocean GCMs. J Geophys Res 105:23927-23942
Smith NR (1995) The BMRC ocean thermal analysis system. Aust Meteor Mag 44:93-110

Springer SR, Mcphaden MJ, Busalacchi AJ (1990) Oceanic heat content variability in the tropical pacific during the 1982-1983 El Niño. J Geophys Res 95(C12): 22,089-22,101. doi:10.1029/ JC095iC12p22089

Strutton PG, Chavez FP (2004) Radiant heating in the equatorial Pacific: observed variability and potential for real-time calculation. J Clim 17:1097-1109

Vialard J, Menkes C, Boulanger JP, Delecluse P, Guilyardi E, McPhaden MJ, Madec G (2001) Oceanic mechanisms driving the SST during the 1997-1998 El Niño. J Phys Oceanogr $31: 1649-1675$

Walin G (1982) On the relation between sea-surface heat flow and thermal circulation in the ocean. Tellus 34:187-195

Wang F, Dunxin HU (2010) Introduction to international NPOCE program. Chin J Ocean Limnol 28:953. doi:10.1007/s00343010-0953-7

Wang C, Picaut J (2004) Understanding ENSO physics-a review (2004). In: Wang C, Xie SP, Carton JA (eds) Earth climate: the ocean-atmosphere interaction. AGU geosphysical mono-graph series, pp 1-54

Wetzel P, Maier-Reimer E, Botzet M, Jungclaus J, Keenlyside N, Latif M (2006) Effects of ocean biology on the penetrative radiation in a coupled climate model. J Clim 19:3973-3987

Wyrtki K (1985) Water displacements in the Pacific and the genesis of El Niño cycles. J Geophys Res 90:7129-7132

Large WG, Yeager, SG (2004) Diurnal to decadal global forcing for ocean and sea-ice models. NCAR technical note. $22 \mathrm{pp}$

Zhang YC, Rossow WB, Lacis AA, Oinas V, Mishchenko MI (2004) Calculation of radiative fluxes from the surface to top of atmosphere based on ISCCP and other global data sets: refinements of the radiative transfer model and the input data. J Geophys Res 109:27 